\title{
The comparative analysis of historical alien introductions
}

\author{
Daniel Sol · Montserrat Vilà $\cdot$ Ingolf Kühn
}

Received: 20 June 2007 / Accepted: 19 October 2007/Published online: 21 November 2007

(C) Springer Science+Business Media B.V. 2007

\begin{abstract}
The comparative analysis of past introductions has become a major approach in investigating the rules governing invasions, yet their utility to understand the invasion process is not exempt of problems. The relevance of some of these problems has not yet been fully appreciated, but it has now become clear that not taking them into account may lead to invalid conclusions. Taking examples of the plants' and birds' literature, this paper reviews these difficulties by discussing the comparative analysis of region invasibility. The difficulties include biased information toward successful introductions, confounded effects of many explanatory variables, statistical non-independence of introduction events and taxonomic levels, and inappropriate definition of the units of study. Provided that there is good information on introduction events at the appropriate spatial scale, reliable results may be obtained by using
\end{abstract}

D. Sol $(\bowtie)$

Centre for Ecological Research and Applied Forestry

(CREAF), Autonomous University of Barcelona,

E-08193 Bellaterra, Catalonia, Spain

e-mail: d.sol@creaf.uab.es

M. Vilà

Estación Biológica de Doñana (EBD-CSIC), Avd/ Ma

Luisa s/nPabellón del Perú, 41013 Sevilla, Spain

I. Kühn

Department of Community Ecology (BZF),

UFZ-Helmholtz-Centre for Environmental Research,

Theodor-Lieser-Strasse 4, 06120 Halle, Germany modelling techniques that control for the effects of introduction effort and species properties while dealing with spatial and phylogenetic non-independence of introduction events. In conclusion, although important progress can be made in understanding the factors behind invasibility of regions by the comparative analysis of the past introductions, this will only be possible by acknowledging the existence of biases and confounding effects in historical introductions and by using appropriate methods to deal with them.

Keywords Invasion success - Invasibility · Comparative approach - Statistical techniques · Phylogenetic-based methods . Spatial autocorrelation · Pseudoreplication

\section{Introduction}

Concern over the impact of invaders on biodiversity and ecosystem functioning has prompted a plethora of research on the mechanisms that govern biological invasions. Much of the effort has been devoted to designing and performing experiments in the field and in controlled conditions. Experiments are the best approach to establish causal relationships, and hence are central to understanding the mechanisms of invasion (Schoener and Spiller 1999; Levine 2000; Levine et al. 2003). However, experiments are by itself insufficient to fully understand invasions. Due 
to the immense variability of ecological systems, one limitation of experiments is that the results might lack generality, being only related to the particular area, period of time or species selected as study case. Moreover, not all questions on invasions can be tackled by experimentation, for example those concerned to the resistance of entire regions to invaders. Finally, experiments are not always possible for taxa such as long-lived plants or vertebrates in which natural, large scale experimental introductions are not feasible for legal, ethical or logistic reasons.

One alternative to the experimental approach is the comparative analysis of past introductions (Kolar and Lodge 2001; Fisher and Owens 2004; Cadotte et al. 2006). In the last decades, the use of the comparative approach has greatly broadened our understanding of the invasion process, uncovering some of the general rules that govern the establishment and spread of species introduced into foreign regions (Brown 1989; Lodge 1993; Kolar and Lodge 2001; Duncan et al. 2003; Fisher and Owens 2004; Cadotte et al. 2006). A major advantage of the comparative approach is that it can help drawing general principles that apply over broad regions and across a great diversity of taxa, and may thus provide generalities that are realistic enough to be used in risk assessment of future invaders as well as provide the starting place for determining management of existing invasions (Kolar and Lodge 2002; Settele et al. 2005). The comparative approach can be used to evaluate a variety of hypotheses regarding the invasion process, such as identifying the properties that make some species successful invaders or assessing whether habitats differ in their resistance to invaders (Kolar and Lodge 2001; Sakai et al. 2001; Duncan et al. 2003). Human-driven introductions have thus been considered as one of the most important, albeit unfortunate, "ecological experiments" ever conducted (Rice and Sax 2005).

Yet, past introductions are not well-designed experiments, but quasi-experiments (see Table 1), and hence their utility for understanding the invasion process is not free of problems. In short, the problems of analysing past introductions arise from the nonrandom assignment of the species to the introduced regions, the impossibility of isolating a priori single treatment effects, and the lack of true replication, all of which makes the approach vulnerable to a number of biases and confounding effects that prevents inferring causality. The relevance of some of these issues is, in our view, not fully appreciated, even though evidence indicates that not taking them into account may lead to invalid conclusions (Cassey et al. 2004). Continuing to add to this body of work without acknowledging the limitations of the comparative approach will do relatively little to advance our understanding of the invasion process.

Here, we constructively review the difficulties to detangle the factors underlying the process of invasion using the record of past introductions. We illustrate these difficulties by discussing the comparative analysis of region invasibility, defined as the ease with which new species become established in a region where they are introduced (Lonsdale 1999), although most of the difficulties also apply to other aspects of the invasion process. Our intention is not to exhaustively review the progress made to understanding invasibility with the use of the comparative approach, an issue that has been reviewed elsewhere (Smallwood 1994; Levine and D'Antonio 1999; Shea and Chesson 2002; Cadotte et al. 2006; Colautti et al. 2006). Rather, we use the concept of invasibility to illustrate the different caveats of the comparative approach when applied to historical introductions. Our goal is to illustrate with examples the nature of the problems, and then present some of the approaches to deal with them.

\section{Confounding invasibility with invader pools}

A main complication in assessing whether regions differ in invasibility is the necessity to disentangle the effects of the region from those associated with the frequency of introductions. The fact that some regions contain more invaders than others may simply reflect differences between regions in the number of species introduced deliberately or accidentally by humans (Lonsdale 1999). For example, a consistent pattern that emerges from the study of past introductions is that the number and proportion of naturalized aliens on islands is generally higher than in continents. In New Zealand, for instance, the number of naturalized birds is more than two times higher than that of Australia (Duncan et al. 2003). Such type of evidence has been used to support the viewpoint that island communities are more invasible than those of mainland areas, yet they simply reflect 
Table 1 Comparison between experimental and comparative approaches in the study of differences in invasibility among regions

\begin{tabular}{|c|c|c|}
\hline Aspect to consider & Experiment & Comparative analysis \\
\hline Grain of the spatial scale & Fine & Coarse \\
\hline Spatial autocorrelation & Controlled & $\begin{array}{l}\text { Uncontrolled, usually present. Should be included in } \\
\text { the analysis }\end{array}$ \\
\hline \multirow[t]{2}{*}{ Temporal scale } & Contemporaneous & Past \\
\hline & $\begin{array}{l}\text { Usually short, medium if permanent plots } \\
\text { or long-term experiment available }\end{array}$ & $\begin{array}{l}\text { Usually long, sometimes unknown if residence time } \\
\text { was not recorded }\end{array}$ \\
\hline Causality & Demonstrated by treatment manipulation & $\begin{array}{l}\text { Inferred from statistical analysis with multiple } \\
\text { predictors }\end{array}$ \\
\hline Replication & $\begin{array}{l}\text { True and random } \\
\text { Low due to logistic and man-power constraints }\end{array}$ & $\begin{array}{l}\text { Not random, biased towards certain regions and } \\
\text { species } \\
\text { Large sample size if many records available }\end{array}$ \\
\hline Phylogenetic inertia & $\begin{array}{l}\text { Considered as a fixed species effect } \\
\text { because usually few species are tested }\end{array}$ & $\begin{array}{l}\text { Considered as a random effect because usually the } \\
\text { alien species dataset is large }\end{array}$ \\
\hline Propagule pressure & Absent or controlled & $\begin{array}{l}\text { Present and uncontrolled } \\
\text { Should be estimated in the analysis even if only } \\
\text { surrogates are available }\end{array}$ \\
\hline Invasiveness & Controlled & $\begin{array}{l}\text { Uncontrolled. Species traits should be included } \\
\text { in the analysis }\end{array}$ \\
\hline Logistical considerations & $\begin{array}{l}\text { Field experimentation with birds is } \\
\text { almost impossible }\end{array}$ & Advanced statistical software required \\
\hline Ethical considerations & $\begin{array}{l}\text { High if experimental introductions are } \\
\text { required }\end{array}$ & Absent \\
\hline
\end{tabular}

the fact that humans had introduced more species to islands than to continents (Duncan et al. 2003).

The success in the comparative analysis of region invasibility depends thus on the availability of accurate information on the pool of introduced species (Duncan et al. 2003). While the species that have succeeded at establishing themselves are relatively easy to determine, it is much more difficult to know those that have failed, as they may have left no traces of their presence in the region. Indeed, for many taxa the record of species unsuccessfully introduced is quite incomplete. In plants, for example, we can recall on only a few studies which have attempted to estimate the success of naturalization based on species introductions rates (e.g. Duncan and Williams 2002).

The incapacity to control for the invader pools limits the possibility of using the comparative approach for some taxa (Lonsdale 1999). In addition, for those taxa for which information is available, the existence of differences in the quality of the historical record may lead to wrong conclusions when comparing invasibility among regions, the ecosystem resistance to invaders being under-estimated in regions with a poorer record of failed introductions. Fortunately, appropriate data sets can be found for many plant and animal taxa. For example, Duncan and Williams (2002) used exotic angiosperm and gymnosperm species that have been introduced for cultivation into New Zealand to show that naturalization success is higher for introduced species belonging to genera already found in New Zealand, contradicting Darwin's naturalization hypothesis (but see Lambdon and Hulme 2006; Ricciardi and Mottiar 2006).

\section{Confounding invasibility with propagule pressure}

Accurate records of introduction successes and failures are not enough to study invasibility. We also need information on the effort with which the different species have been introduced. All evidence to date indicate that species that are introduced in larger numbers or more times are more likely to become established than those that are introduced in smaller numbers or fewer times (Lockwood et al. 2005), as the latter are highly vulnerable to extinctions by 
demographic or genetic stochasticity (Legendre et al. 1999; Sax and Brown 2000). If species have tended to be introduced in larger number in some regions than in others (Cassey et al. 2004), this may lead us to erroneously conclude that they differ in invasibility.

Information on introduction effort is available in some cases of deliberate introductions, making it possible to control for the above biases with the appropriate statistical techniques (Table 2). In birds, for example, many of the introductions in the 18th and 19th centuries occurred during the great migrations of European settlers (Long 1981), a major motivation being that the introduced species reminded them of their European homeland. The process of transporting and introducing species was facilitated by the setting up of acclimatization societies, which kept accurate records of the year of introduction, its outcome and even the number of individuals released, providing high quality data that have been the basis of many comparative studies (e.g. Veltman et al. 1996; Green 1997).

The problem of confounding invasibility with introduction effort is particularly difficult to overcome in the case of plant invasions, given the obvious difficulties in measuring the number of seeds released and considering that many plant species have been introduced accidentally. Furthermore, the number of introduction attempts, which may be correlated with the number of introduced individuals (Veltman et al. 1996), is also of little use in this case, as the role of humans in secondary releases is virtually impossible to assess. However, there have been some imaginative attempts to deal with these limitations. For example, given that the effort of introduction is a function of human activities (Chaloupka and Domm 1986), some authors have suggested using the number of human visitors to an area as surrogate for propagule pressure in plants (Pysěk et al. 2002; Sobrino et al. 2002; McKinney 2004). This type of approaches can be useful provided that one can show a priori that the chosen variable is an appropriate surrogate for propagule pressure. For the above example, the assumption that the amount of human visitors to an area reflect propagule pressure is supported by the existence of a positive relationship between number of visitors and the percentage of alien plants in the area (e.g. Chaloupka and Domm 1986).

\section{Confounding invasibility with invasiveness}

Another complication in assessing whether regions differ in invasibility is the need to disentangle the effects of the region from those associated with invasiveness (i.e. invasion potential of the species introduced). To become established in a novel region, a species needs to find an appropriate niche there. The chances of finding a niche opportunity will depend on the presence of preys, competitors and enemies or pathogens in the community, but also will depend on the properties of the introduced species (Sol 2007). In fact, there is evidence that species differ in their invasion potential in virtue of their properties. In birds, successful invaders tend to be habitat generalists (Cassey et al. 2004) and to show a high degree of flexibility in their behaviour (Sol et al. 2005). In plants, more abundant naturalized species tend to have wider niche breadths regarding habitat and climate (Kühn et al. 2004). If species with features of successful invaders have been introduced more often in some regions than in others, this may lead us to believe that regions differ in invasibility when this is just a confounding effect of its co-variation with species properties.

There is evidence that the identity of the species introduced is non-random. In birds, most of the species chosen for introduction come from temperate regions, and hence it is expected that traits characteristic of the taxa in these regions are overrepresented (Duncan et al. 2003). Moreover, introductions of behaviourally flexible species have been more frequent in some regions than in others (Sol et al. 2005). Thus, the risk is high that differences between regions in the likelihood of establishment are confounded by the invasion potential of the species introduced. This might be one of the reasons why species attributes related to invasion success differ depending upon the habitat type (Lloret et al. 2005) and spatial extent of the region to be analysed (Hamilton et al. 2005).

Assessing the effects of the region from those associated with propagule pressure and the properties of the introduced species is thus central to assess whether or not regions differ in invasibility. This requires statistical control of these factors using techniques such as multi-variable models (Veltman et al. 1996) or path analysis (Duncan et al. 1999; Sol et al. 2005). 
Table 2 Overview on some software for methods to correct for phylogenetic or spatial non-independence or both

\begin{tabular}{|c|c|c|}
\hline Software & Method & Source \\
\hline \multicolumn{3}{|l|}{ Spatial analyses only } \\
\hline $\begin{array}{l}\text { SAM (spatial analysis in } \\
\text { macroecology) }\end{array}$ & $\begin{array}{l}\text { Conditional autoregressive models, } \\
\text { simultaneous autoregressive models, } \\
\text { spatial filtering, spatial generalized } \\
\text { least squares }\end{array}$ & Rangel et al. (2006) http://www/ecoevol.ufg.br/sam/ \\
\hline SpaceStat & Simultaneous autoregressive models & $\begin{array}{l}\text { Anselin (1995) } \\
\text { http://www.terraseer.com/products/spacestat.html }\end{array}$ \\
\hline \multicolumn{3}{|l|}{ Phylogenetic analyses only } \\
\hline $\begin{array}{l}\text { CAIC (Comparative analysis by } \\
\text { independent contrasts) }\end{array}$ & Phylogenetic independent contrasts (PIC) & $\begin{array}{l}\text { Pruvis and Rambaut (1995) } \\
\text { http://www.bio.ic.ac.uk/evolve/software/caic/ }\end{array}$ \\
\hline $\begin{array}{l}\text { COMPARE (Phylogenetic } \\
\text { comparative methods) }\end{array}$ & $\begin{array}{l}\text { Independent contrasts, phylogenetic } \\
\text { generalized least squares, phylogenetic } \\
\text { mixed model }\end{array}$ & Martins (2004) http://compare.bio.indiana.edu/ \\
\hline $\begin{array}{l}\text { CACTUS (Comparative analysis } \\
\text { of continuous traits using } \\
\text { statistics) }\end{array}$ & Independent contrasts & $\begin{array}{l}\text { Schwilk and Ackerly (2001) } \\
\text { http://www.pricklysoft.org/software/cactus.html }\end{array}$ \\
\hline
\end{tabular}

Both phylogenetic as well as spatial analyses

$\mathrm{R}$ (different packages)

R Development Core Team (2006)

http://www.r-project.org/

ape (Analyses of phylogenetics Phylogenetic independent contrasts (PIC), Paradis and Claude (2002)

and evolution) Generalized estimating equations

(GEE) in a phylogenetic context

PHYLOGR (Functions for phylogenetically based statistical analyses)

GEE (Generalized estimation equation solver), geepack; available for R and SPLUS

MASS (Modern applied statistics with S), lme4 (Linear mixed-effects models using S4 classes), nlme (Linear and nonlinear mixed effects models); available for $\mathrm{R}$ and SPLUS

stats

spdep (Spatial dependence: weighting schemes, statistics and models)

SPLUS

Spatial module in SPLUS

GLIMMIX in SAS
Generalized least square models (GLS) in a phylogenetic context

Generalized estimating equations

General(ized) mixed effect models/ Generalized least squares models

Eigenvalue-based filtering

R Development Core Team (2006)

Conditional autoregressive models, simultaneous autoregressive models, spatial filtering

Generalized mixed effect models/ Generalized least squares models

Generalized estimating equations

Conditional autoregressive models, simultaneous autoregressive models

Generalized mixed effect models/ Generalized least squares models
Bivand et al. (2006)

http://www.s-plus.com/

Pinheiro and Bates (2000)

Yan and Fine (2004)

http://www.sas.com/

There is a plethora of methods and software implementations available and we will only be able to present some few examples. Many of the programmes mentioned are able to do many more analyses. The list is by far not exhaustive. The spelling (including use of upper and lower case) is in accordance with the programmes themselves 


\section{Using the appropriate spatial level of analysis}

Some comparative analyses have defined the regions of study based on geographical criteria rather than based on ecological similarity. While this may be appropriate for the specific purposes of these studies, examining regions with high heterogeneity in climatic and ecological characteristics is clearly inappropriate to study invasibility. All introductions into large countrywide regions (e.g. North America, Australia, etc.) should not be regarded as equivalent, as it seems clear that ecological differences within these large regions may in some cases be larger than among regions. These limitations may have concealed interesting patterns that could be important for better understanding the process of invasion (Kark and Sol 2005). One clear example is the finding in large-scale analyses that more diverse systems contain higher numbers of exotic species (Shea and Chesson 2002), an observation that is contrary to theory (Elton 1958). This discrepancy is attributed to extrinsic factors that vary at these spatial scales, which favour high numbers of native species and also increase niche opportunities for invaders (see Kühn and Klotz 2007 for details).

Thus, tests of the factors that make some regions more invasible than others should also define regions in a more ecological way (Kark and Sol 2005). The problem is that with historical introductions it often is difficult to know the exact environment where species have been introduced. Moreover, in mobile organisms, as in birds, the place of introduction can differ from the place of establishment. One possibility to overcome these difficulties is to restrict the analyses to islands (Cassey et al. 2005; see below), as ecological differences within island should generally be smaller than across islands. An alternative is to compare invasions across convergent ecosystems that share similar climates (Kark and Sol 2005). Such an approach enables one to investigate patterns and processes that affect the success and failure of species introductions while adjusting for fundamental climate region and ecosystem-type differences. Comparing convergent Mediterranean ecosystems, Kark and Sol (2005) reported evidence that regions are differentially invaded by birds, with the Mediterranean Basin showing higher invasibility than Mediterranean Australia and the South African Cape.

\section{Spatial non-independence of introduction events}

Theory predicts a number of reasons why some regions and ecosystems should be easier to invade than others, including variation in climatic conditions, species diversity and degree of environmental disturbance (Williamson 1996; Shea and Chesson 2002). However, if it is easier to establish at some locations than others, then the outcome of introductions to the same location will be correlated (Duncan et al. 2003). This means that introductions in the same region are unlikely to represent independent pieces of evidence for the influence of a factor on establishment success, because we should expect similar outcomes (either success of failure) for all species introduced to the same location, violating a core assumption of standard statistical tests. The pseudo-replication that arises if the probability of success in introductions is more similar between near-by regions than it is between more distant regions is the so-called spatial autocorrelation (SAC). The above-mentioned example of repeated introductions in the same region is the most extreme form of spatial non-independence or pseudo-replication.

Spatial autocorrelation can be particularly problematic in studies trying to characterize the factors that make some regions more resistant to invaders than others. On one hand, when data points are not independent, statistical tests are more likely to show that factors have a significant influence on establishment success when actually they have not (type I error). Maybe even more important, albeit less often appreciated, is the fact that ignoring SAC may yield incorrect parameter estimates for slopes and intercept (see Lennon 2000; Lichstein et al. 2002) as far as changing the direction of a relationship (Kühn 2007). On the other hand, if some of the characteristics that make some regions more resistant to invaders than others follow a similar pattern of autocorrelation than establishment success, then the association between these characteristics and establishment can be entirely caused by their geographical distribution (i.e. spatial) pattern. Therefore, ignoring SAC may often increase the variance around parameter estimates but not necessarily yield incorrect results as such (Hawkins et al. 2007).

There are several methods now available that correct for spatial non-independence (Table 2, see also review by Dormann et al. 2007). If we only want 
to correct for a "region" effect in invasion analysis, we can do so with a (generalized) mixed effect model, such as in Blackburn and Duncan (2001), where the region is coded as a random effect. However, this would only correct for the effect of that "region" but would disregard smaller scale SAC. If we have information on spatial coordinates, then we should check for SAC of the residuals (e.g. computing Moran's I). If SAC is present, the choice of methods is relatively easy when the data (or better the residuals) are normally distributed. For such data, there are broadly two classes of methods: conditional autoregressive methods (CAR) and simultaneous autoregressive methods (SAR) (Cliff and Ord 1981; Anselin 1988; Cressie 1993; Haining 2003; see Kissling and Carl 2008, for details in an ecological framework). With non-normally distributed data, such as binomial or Poisson, we will need a generalization of the methods described above. Generalized Estimating Equations (GEE) are generalizations of Generalized Linear Models (GLM) to include autocorrelation structures (Diggle et al. 1995; Yan and Fine 2004; Carl and Kühn 2007). Another option is the use of Generalized linear mixed effect models (Blackburn and Duncan 2001) or the use of and Generalized Least Squares, which are also apt to correct for SAC in analyses with non-normally distributed residuals when a correlation structure is defined. Diniz-Filho and Bini (2005) used an approach using spatial eigenvectors as covariates in a regression model as a useful tool. Very recently, Carl and Kühn (2008) developed a wavelet-revised method which proved to be very fast, stable and efficient in accounting for SAC when having gridded data. The use of the very popular autologistic methods, however, yields severe bias and incorrect parameter estimates and hence cannot be recommended (Carl and Kühn 2007; Dormann et al. 2007). The methods briefly introduced here are described in more detail by Dormann et al. (2007).

\section{Phylogenetic non-independence of introduction events}

Besides the likely non-independence between introduction events or spatial arrangements, species are themselves clustered to higher level units. This phylogenetic non-independence essentially mirrors the effects of spatial non-independence and may therefore have similar problems. In particular, closely related species share many morphological, behavioural, physiological and ecological traits due to common ancestor rather than independent evolution (Felsenstein 1985; Harvey and Pagel 1991; Freckleton et al. 2002). If these shared traits affect the likelihood of establishment, then introduction outcomes will be clustered by phylogenetic or taxonomic relatedness. In other words, spatial proximity is exchanged by phylogenetic relatedness. Not taking into account the phylogenetic relationship between species overestimates the degrees of freedom in the analysis and increases the chance to obtain false positives. Additionally, phylogenetic relatedness that overlaps with environmental influences (e.g. due to niche conservatism) may interfere with such variables and lead to wrong parameter estimates. The importance of considering phylogenetic relationships when comparing species has long been recognized (Felsenstein 1985; Harvey and Pagel 1991; Freckleton et al. 2002). A simple example can illustrate the problem when studying the invasibility of regions. Let's imagine that we want to test whether an ecological factor such as the degree of disturbance in the habitat facilitates establishment and survival of invaders, and we manage to obtain good data for 40 species' introductions to do so (Fig. 1). In phylogenetically uninformed tests, these 40 species would be used as pieces of evidence to support or reject the hypothesis. As shown in Fig. 1a, in our working

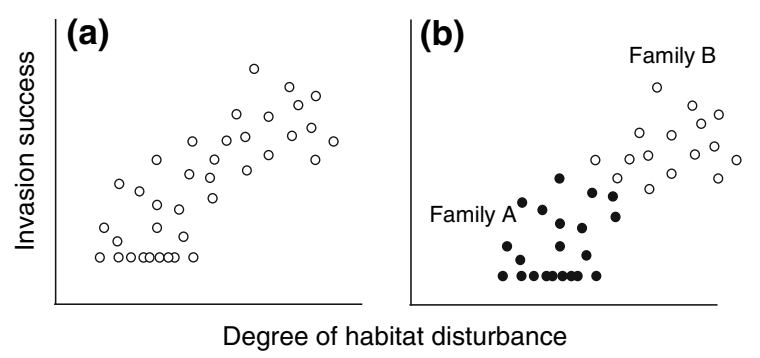

Fig. 1 Example of phylogenetic effects in interspecific comparisons $(n=40)$. In this example the graph (a) would suggest a link between an ecological variable such as degree of habitat disturbance and invasion success (e.g. species establishment or survival) when the association is the result of taxonomic relationship (b). Not taking into account the phylogenetic relationship between species may thus overestimate the degrees of freedom in the analysis and increases the chance to obtain false positives (See text for further details) 
example the test would support the hypothesis that disturbance facilitates invasion. Let's now imagine that these species belong to only two different families, and that species from each family differ in their ability to survive in disturbed habitats (Fig. 1b). Would we still consider that there are 40 pieces of evidence? Figure $1 \mathrm{~b}$ does not suggest any pattern within families, but just differences between them. Species from a same family are likely to share many characters thought to affect establishment that could be confounding the association. We only really have two independent data points with 20 pseudoreplicates, each, which is certainly not enough from which to draw any firm conclusions.

The degree of phylogenetic autocorrelation in a variable can be evaluated by a number of methods, including the Moran's I autocorrelation index (Paradis and Claude 2002) or phylogenetic generalized least squares (Freckleton et al. 2002). If phylogenetic effects are proved to be important, these should be controlled for either with methods aimed at removing phylogenetic influence from trait spaces (such as phylogenetic independent contrasts; (Felsenstein 1985) or with those that partition their influence between environment and phylogeny (such as eigenfactor based methods; Diniz-Filho et al. 1998; Desdevises et al. 2003). The eigenvector approach was used by Lososová et al. (2006) in an analysis of trait patterns in annual vegetation of man-made habitats in central Europe. There, among other results, alien status changed from insignificant to significant after accounting for phylogenetic information. When no adequate phylogenetic hypothesis is available, the problem of phylogenetic inertia may be partially solved by using taxonomic information. For example, the systematic hierarchy may be incorporated in (Generalized) Mixed effect Models as random effect (Cassey et al. 2004; Duncan and Blackburn 2004; Sol et al. 2005) or as autocorrelation matrix in Generalised Estimating Equations (GEE) (Duncan and Blackburn 2004).

\section{Introduced success of birds as an example}

The main conclusion drawn from the previous section is that to properly study region invasibility we not only need good information on introduction events at the appropriate spatial level, but we also need to employ statistical techniques that can control for confounding variables (introduction effort and species properties) and incorporate information on non-independence of introduction events due to phylogenetic affiliation and SAC, so as to produce unbiased estimates of the effects of the different factors. As previously shown, there are several modelling approaches now available to do so. Admittedly, some of the advanced approaches are cumbersome in analysis and interpretation, and several are far from being perfect. However, it is better to use some improved though not perfect statistical method than a method where the basic assumptions are clearly violated.

Only a few studies have adopted the above principals to examine differences in invasibility between regions. One of these few examples is the analysis by Cassey et al. (2004) of global patterns of establishment success in birds. Following Blackburn and Duncan (2001), the likely non-independence of introductions of the same taxa or in the same region was modelled by using Generalized Linear Mixed Models (GLMM). The approach used was to assume a common positive correlation between introduction outcomes within the same taxa or region, but a zero correlation between outcomes involving different taxa or regions. This was achieved by including region of introduction and the taxonomic hierarchy as random effects in the model. Because the response variable was success or failure of introductions, Cassey et al. (2004) adopted a model with binomial structure of errors. The results confirmed the primary importance of propagule pressure for avian establishment success across regions. Moreover, propagule size was found to be correlated with a large number of variables previously thought to influence success. From all those variables, only habitat generalism was related to establishment success once the effect of propagule was controlled for with a multi-variable approach. The number of released individuals was not only the strongest correlate of introduction success, but was also non-randomly distributed across regions. Thus, differences between regions in invasibility could not be assessed without considering the confounding effects of propagule size and nonrandom distribution of species with varying invasion potential. When propagule size and habitat generalism were controlled for in the model, Cassey et al. (2004) found significant differences in the likelihood of establishment of birds across regions. For example, 
while $56 \%$ of avian releases succeeded in Hawaii, only $35 \%$ succeeded in New Zealand.

When a comparative analysis has shown that regions do differ in invasibility, the next step is of course to try to understand why regions differ in invasibility. Provided that one defines the study units in ecological terms and uses appropriate statistical techniques, the comparative method may provide important insight into the factors that make some regions more invasible than others. Cassey et al. (2005), for example, used information for exotic bird introductions to oceanic islands and archipelagos around the globe to test whether invasibility is related to competition, predation, human disturbance or habitat diversity. Islands seem to be an appropriate unit of analyses, as ecological differences within each island should generally be smaller than across islands. Once controlled for confounding effects and spatial and taxonomic autocorrelation, there was a strong negative interaction across regions between establishment success and predation; exotic birds are more likely to fail on islands with species-rich mammalian predator assemblages.

\section{Conclusions}

In this review, we argue that the comparative analysis of past introductions can provide important insight into the factors that make some regions more invasible than others. However, we also highlight that the comparative analysis is only useful as long as the problems of this approach are fully appreciated, and these are mitigated by the use of appropriate methods. Because the risk of mistakes and biases is high for historical data, and because the chances to detect biologically meaningful signal can be significantly reduced when the information is inaccurate, checking whether the available information is reliable remains central in the comparative analyses of past introductions. Provided that this information is accurate, reliable results may be obtained by using appropriate modelling techniques that control for the effects of introduction effort and species properties while dealing with spatial and phylogenetic non-independence of introduction events. Of course, it can happen that some important questions can be addressed only by using relatively imperfect data (e.g. small data sets), but this should not prevent the use of comparative methods as long as these imperfections do not alter the conclusions. Thus, rather than advocate for a conservative approach, which can reduce the probability of obtaining false positives (type I error) but at the expenses of increasing that of false negatives (type II error), we suggest a precautionary approach in which the limitations of the method are fully acknowledged and the assumptions adopted are reasonably wellsupported. Used correctly, the comparative method can be a powerful tool to identify general principles underpinning the invasion process that apply over broad regions and across a great diversity of taxa. Yet used inadequately, the method will do relatively little to advance our understanding of the invasion process and may even yield incorrect results.

Acknowledgements We thank Richard Duncan, Tim Blackburn, Phil Cassey, Louis Lefebvre, J. A. F. Diniz-Filho, Phil Hulme, Petr Pysěk, Joan Pino, Salit Kark, Sven Bacher, Gudrun Carl, Andreas Prinzing and Gray Stirling for fruitful discussions over the past years. This work was supported by a "Ramón y Cajal" fellowship and a "Proyecto de Investigación" (ref. CGL2005-07640/BOS) from the Ministerio de Educación y Ciencia (Spain) to DS, and European Commission 6th Framework Programme Integrated Project ALARM (Assessing LArge scale environmental Risks for biodiversity with tested Methods) Grant GOCE-CT-2003-506675 (Settele et al. 2005).

\section{References}

Anselin L (1988) Spatial econometrics: methods and models. Kluwer, Dordrecht

Anselin L (1995) Local indicators of spatial associationLISA. Geogr Anal 27:93-115

Blackburn TM, Duncan RP (2001) Determinants of establishment success in introduced birds. Nature 414:195-197

Bivand R, Anselin L, Berke O, Bernat A, Carvalho M, Chun Y, Dormann C, Dray S, Halbersma R, Lewin-Koh N, Ono H, Peres-Neto P, Tiefelsdorf M, Yu D (2006) spdep: Spatial dependence: weighting schemes, statistics and models. [R package]. http://www.r-project.org/

Brown JH (1989) Patterns, modes and extents of invasions by vertebrates. In: Drake JA, Mooney HA, di Castri F, Groves RH, Kruger FG, Rejmanek M, Williamson M (eds) Biological invasions: a global perspective. John Wiley Sons, Chichester, pp 85-109

Cadotte MW, Murray BR, Lovett-Doust J (2006) Ecological patterns and biological invasions: using regional species inventoriesin macroecology. Biol Invasions 8:809-821

Carl G, Kühn I (2007) Analyzing spatial autocorrelation in species distributions using Gaussian and Logit models. Ecol Model 207:159-170

Carl G, Kühn I (2008) Analyzing spatial ecological data using linear regression and wavelet analysis. Stoch Environ Res Risk Assess (in press). doi:10.1007/s00477-007-0117-2 
Cassey P, Blackburn TM, Sol D, Duncan RP, Lockwood JL (2004) Global patterns of introduction effort and establishment success in birds. Proc R Soc Lond Ser B 271:S405-S408

Cassey P, Blackburn TM, Duncan RP, Gaston KJ (2005) Causes of exotic bird establishment across oceanic islands. Proc R Soc Lond Ser B 272:2059-2063

Chaloupka MY, Domm SB (1986) Role of anthropochory in the invasion of coral cays by alien flora. Ecology 67: $1536-1547$

Cliff AD, Ord JK (1981) Spatial processes: models and applications. Pion, London

Colautti RI, Grigorovich IA, MacIsaac HJ (2006) Propagule pressure: a null model for biological invasions. Biol Invasions 8:1023-1037

Cressie NAC (1993) Statistics for spatial data. Wiley, Cambridge

Desdevises Y, Legendre P, Azouzi L, Morand S (2003) Quantifying phylogenetically structured environmental variation. Evolution 57:2647-2652

Diggle PJ, Liang KY, Zeger SL (1995) Analysis of longitudinal data. Clarendon, Oxford

Diniz-Filho JAF, Bini LM (2005) Modelling geographical patterns in species richness using eigenvector-based spatial filters. Global Ecol Biog 14:177-185

Diniz-Filho JAF, De Santana CER, Bini LM (1998) An eigenvector method for estimating phylogenetic inertia. Evolution 52:1247-1262

Dormann CF, McPherson JM, Araújo MB, Bivand R, Bolliger J, Carl G, Davies RG, Hirzel A, Jetz W, Kissling WD, Kühn I, Ohlemüller R, Peres-Neto PR, Reineking B, Schröder B, Schurr FM, Wilson R (2007) Methods to account for spatial autocorrelation in the analysis of species distributional data: a review. Ecography 30(5):609-628

Duncan RP, Williams PA (2002) Darwin's naturalization hypothesis challenged. Nature 417:608-609

Duncan RP, Blackburn TM (2004) Extinction and endemism in the New Zealand avifauna. Global Ecol Biogeogr 13:509-517

Duncan RP, Blackburn TM, Veltman CJ (1999) Determinants of geographical range sizes: a test using introduced New Zealand birds. J Anim Ecol 68:963-975

Duncan RP, Blackburn TM, Sol D (2003) The ecology of avian introductions. Ann Rev Ecol Evol Syst 34:71-98

Elton CS (1958) The ecology of invasions by animals and plants. University Chicago Press, Chicago

Felsenstein J (1985) Phylogenies and the comparative method. Am Nat 125:1-15

Fisher DO, Owens IPF (2004) The comparative method in conservation biology: extinction, introduction and invasion. Trends Ecol Evol 19:391-398

Freckleton RP, Harvey PH, Pagel M (2002) Phylogenetic analysis and comparative data: a test and review of evidence. Am Nat 160:712-726

Green RE (1997) The influence of numbers released on the outcome of attempts to introduce exotic bird species to New Zealand. J Anim Ecol 66:25-35

Haining RP (2003) Spatial data analysis: theory and practice. Cambridge University Press, Cambridge

Hamilton MA, Murray BR, Cadotte MW, Hose GC, Baker AC, Harris CJ, Licari D (2005) Life-history correlates of plant invasiveness at regional and continental scales. Ecol Lett 8:1066-1074

Harvey PH, Pagel MD (1991) The comparative method in evolutionary biology. Oxford University Press, Oxford

Hawkins BA, Diniz-Filho JAF, Bini ML, De Marco P, Blackburn TM (2007) Red herrings revisited: spatial autocorrelation and parameter estimation in geographical ecology. Ecography 30:375-384. doi:10.1111/j.2007.0906-7590. 05117.x

Kark S, Sol D (2005) Establishment success across convergent Mediterranean ecosystems: an analysis of bird Introductions. Conserv Biol 19:1519-1527

Kissling WD, Carl G (2008) Spatial autocorrelation and the selection of simultaneous autoregressive models. Global Ecol Biogeogr (in press). doi:10.1111/j.1466-8238.2007. 00334.X

Kolar CK, Lodge DM (2001) Progress in invasion biology: predicting invaders. Trends Ecol Evol 16:199-204

Kolar CK, Lodge DJ (2002) Ecological predictions and risk assessment for alien fishes in North America. Science 298:1233-1236

Kühn I (2007) Incorporating spatial autocorrelation may invert observed patterns. Divers Distr 13:66-69

Kühn I, Klotz S (2007) From ecosystem invasibility to local, regional and global patterns of invasive species. In: Nentwig N (ed) Biological invasions. Springer, Heidelberg, pp 181-196

Kühn I, Brandenburg M, Klotz S (2004) Why do alien plant species that reproduce in natural habitats occur more frequently? Divers Distr 10:417-425

Lambdon PW, Hulme PE (2006) How strongly do interactions with closely-related native species influence plant invasions? Darwin's naturalization hypothesis assessed on Mediterranean islands. J Biogeogr 33:1116-1125

Legendre S, Clobert J, Møller AP, Sorci G (1999) Demographic stochasticity and social mating system in the process of extinction of small populations: the case of passerines introduced to New Zealand. Am Nat 153:449-463

Lennon JJ (2000) Red-shifts and red herrings in geographical ecology. Ecography 23:101-113

Levine JM (2000) Species diversity and biological invasions: relating local process to community pattern. Science 288:852-854

Levine JM, D'Antonio CM (1999) Elton revisited: a review of the evidence linking diversity and invasibility. Oikos 87:15-26

Levine JM, Vilà M, D'Antonio CM, Dukes JS, Grigulis K, Lavorel S (2003) Mechanisms underlying the impacts of exotic plant invasions. Proc R Soc Lond Ser B 270:775-781

Lichstein JW, Simons TR, Shriner SA (2002) Spatial autocorrelation and autoregressive models in ecology. Ecol Monogr 72:445-463

Lloret F, Medail F, Brundu G, Camarda I, Moragues E, Rita J, Lambdon P, Hulme PE (2005) Species attributes and invasion success by alien plants on Mediterranean islands. J Ecol 93:512-520

Lockwood JL, Cassey P, Blackburn TM (2005) The role of propagule pressure in explaining species invasions. Trends Ecol Evol 20:223-228

Lodge DM (1993) Biological invasions: lessons for ecology. Trends Ecol Evol 8:133-136 
Long JL (1981) Introduced birds of the world. David Charles, London

Lonsdale WM (1999) Global patterns of plant invasions and the concept of invasibility. Ecology 80:1522-1536

Lososová Z, Chytrý M, Kühn I, Hájek O, Horáková V, Pyšek P, Tichý L (2006) Patterns of plant traits in annual vegetation of man-made habitats in Central Europe. Perspect Plant Ecol Evol Syst 8:69-81

Martins EP (2004) COMPARE, version 4.6. Computer programs for the statistical analysis of comparative data. Department of Biology, Indiana University, Bloomington

McKinney ML (2004) Citizens as propagules for exotic plants: Measurement and management implications. Weed Technol 18:1480-1483

Paradis E, Claude J (2002) Analysis of comparative data using generalized estimating equations. J Theor Biol 218: $175-185$

Pinheiro JC, Bates DM (2000) Mixed-effects models in S and S-PLUS. Statistics and Computing Series. SpringerVerlag, New York

Pruvis A, Rambaut A (1995) Comparative analyses by independent contrasts (CAIC): an Apple Macintosh application for analyzing comparative data. Comput Appl Biosci 11:247-251

Pysĕk P, Kučera T, Jarošík V (2002) Plant species richness of nature reserves: the interplay of area, climate and habitat in a central European landscape. Global Ecol Biogeogr 11:279-289

Rangel TFL, Diniz-Filho JAF, Bini LM (2006) Towards an integrated computational tool for spatial analysis in marcoecology and biogeography. Global Ecol Biogeogr 15:321-327

R Development Core Team (2006) R: a language and environment for statistical computing. $\mathrm{R}$ Foundation for Statistical Computing, Vienna, Austria

Ricciardi A, Mottiar M (2006) Does Darwin's naturalization hypothesis explain fish invasions? Biol Invasions 8: 1403-1407

Rice WR, Sax DF (2005) Testing fundamental evolutionary questions at large spatial and demographic scales - species invasions as an underappreciated tool. In: Sax DF, Stachowicz JJ, Gaines SD (eds) Species invasions: insights into ecology, evolution, and biogeography. Sinauer, Sunderland, pp 291-308
Sakai AK, Allendorf FW, Holt JS, Lodge DM, Molofsky J, With KA, Baughman S, Cabin RJ, Cohen JE, Ellstrand NC, Cauley DE, O'Neil P, Parker IM, Thompson JN, Weller SG (2001) The population biology of invasive species. Ann Rev Ecol Syst 32:305-332

Sax DF, Brown JH (2000) The paradox of invasion. Global Ecol Biogeogr 9:363-371

Schoener TW, Spiller DA (1999) Indirect effects in an experimentally staged invasion by a major predator. Am Nat 153:347-358

Schwilk DW, Ackerly DD (2001) Flammability and serotiny as strategies: correlated evolution in pines. Oikos 94: 326-336

Settele J, Hammen V, Hulme PE, Karlson U, Klotz S, Kotarac M, Kunin WE, Marion G, O'Connor M, Petanidou T, Peterseon K, Potts S, Pritchard H, Pyšek P, Rounsevell M, Spangenberg J, Steffan-Dewenter I, Sykes MT, Vighi M, Zobel M, Kühn I (2005) ALARM: assessing LArge scale environmental Risks for biodiversity with tested Methods. GAIA-Ecol Perspect Sci Hum Econ 14:69-72

Shea K, Chesson P (2002) Community ecology theory as a framework for biological invasions. Trends Ecol Evol 17:170-176

Smallwood KS (1994) Site invasibility by exotic birds and mammals. Biol Conserv 69:251-259

Sobrino E, Sanz-Elorza M, Dana E, González-Moreno A (2002) Invasibility of a coastal strip in NE Spain by alien plants. J Veg Sci 13:585-594

Sol D (2007) Do successful invaders exist? Pre-adaptations to novel environments in terrestrial vertebrates. In: Nentwig W (ed) Biological invasions. Springer, Heidelberg, pp 127-141

Sol D, Duncan RP, Blackburn TM, Cassey P, Lefebvre L (2005) Big brains, enhanced cognition, and response of birds to novel environments. Proc Natl Acad Sci USA 102:5460-5465

Veltman CJ, Nee S, Crawley MJ (1996) Correlates of introduction success in exotic New Zealand birds. Am Nat 147:542-557

Williamson MH (1996) Biological invasions. Chapman and Hall, London

Yan J, Fine J (2004) Estimating equations for association structures. Stat Med 23:859-874 